\title{
Inadequate labeling of pork sausages prepared in Corsica causing a trichinellosis outbreak in France
}

\author{
Caroline Ruetsch ${ }^{1}$, Pascal Delaunay ${ }^{1,2, *}$, Alexis Armengaud ${ }^{3}$, Françoise Peloux-Petiot ${ }^{4}$ \\ Jean Dupouy-Camet ${ }^{5}$, Isabelle Vallée ${ }^{6}$, Bruno Polack ${ }^{6}$, Pascal Boireau ${ }^{6}$, and Pierre Marty ${ }^{1,2}$ \\ 1 Parasitologie-Mycologie, Hôpital de l'Archet, Centre Hospitalier Universitaire de Nice, 06200 Nice, France \\ 2 Inserm U1065, Centre Méditerranéen de Médecine Moléculaire, Université Nice-Sophia Antipolis, 06000 Nice, \\ France \\ ${ }^{3}$ Cellule de l'Institut de Veille Sanitaire en régions Provence-Alpes-Côte d'Azur et Corse, 13331 Marseille, France \\ 4 Agence Régionale de Santé de Provence-Alpes-Côte d'Azur, 06202 Nice, France \\ 5 Parasitologie-Mycologie, Hôpital Cochin, Assistance Publique Hôpitaux de Paris, 75014 Paris, France \\ 6 ANSES, ENVA, INRA, Université Paris-Est, Laboratoire de Santé Animale ANSES, UMR BIPAR, 94700 Maisons-Alfort, \\ France
}

Received 11 April 2016, Accepted 5 June 2016, Published online 17 June 2016

\begin{abstract}
Three cases of human trichinellosis due to Trichinella britovi were reported in 2015 in the Southeast of France resulting from consumption of raw pork sausages (figatelli) prepared in Corsica. Fourteen other people ate figatelli from the same batch but were not infected due to the figatelli being well cooked. This is the first reported human trichinellosis outbreak due to consumption of Corsican sausages prepared from uncontrolled pork. Consumption of raw figatelli is a common tradition in Corsica. As a result, the health recommendation to cook the product well is not always applied. In the present case, the figatelli product label was not sufficiently visible to advise consumers of the risks associated with uncooked pork.
\end{abstract}

Key words: Trichinellosis, Trichinella, Sausage, Figatelli, Pork, Corsica, France.

Résumé - Un étiquetage insuffisant de saucisses de porc préparées en Corse à l'origine d'une épidémie de trichinellose en France. Trois cas de trichinellose humaine due à Trichinella britovi ont été rapportés en 2015 dans le Sud-Est de la France après consommation de saucisses de porc crues (figatelli) préparées en Corse. Quatorze autres personnes ont mangé des figatelli de ce même lot, mais aucune n'a été infectée car la cuisson des figatelli était à cœur. Nous rapportons la première épidémie de trichinellose humaine due à la consommation de saucisses corses préparées à partir de porc non contrôlé. La consommation de figatelli crue est culturellement ancrée en Corse, et la recommandation d'une cuisson suffisante n'est pas toujours suivie. En effet, la taille de l'étiquette des figatelli était insuffisante pour prévenir les consommateurs des risques associés au porc insuffisamment cuit.

\section{Introduction}

Trichinellosis is a worldwide zoonosis caused by parasitic nematodes of the genus Trichinella, a parasitic worm widespread globally in wildlife and frequent regionally in domestic pigs [7]. Human infections are most common in cultures where dietary habits include consumption of raw or undercooked meat. Trichinellosis can be a serious human disease, particularly in elderly individuals, in whom severe complications such

\footnotetext{
*Corresponding author: delaunay.p@chu-nice.fr
}

as myocarditis or encephalitis can lead to death [3]. The diagnosis of human trichinellosis is based on a set of clinical and biological symptoms associated with epidemiological features. It should be suspected in the presence of a clinical triad including fever, myalgia, and facial edema, associated with high blood eosinophil counts and elevated serum levels of muscle enzymes [3]. The consumption of raw or undercooked meat from game in the previous weeks should be investigated. The diagnosis is confirmed by a positive result for specific serological tests detecting Trichinella antibodies (ELISA, western blot). The identification of larvae in a muscle biopsy from 
the patient is unnecessarily traumatic and not always conclusive, and the parasite can sometimes be detected in remaining contaminated meat. Wild animals act as a reservoir for three species in France: Trichinella spiralis, T. britovi (found more commonly in mountain regions) and more rarely, T. pseudospiralis [10]. In France, 36 outbreaks of trichinellosis occurred between 1975 and 2011 causing 2497 human infections (National Reference Centre for Trichinella). Most of the cases were associated with eight outbreaks related to horsemeat consumption, occurring between 1979 and 1998. Wild boar meat consumption was the source of trichinellosis in 146 cases reported in 24 outbreaks [2, 3], whereas the domestic pig was responsible for only one human infection [4]. This occurred in the South East of France and involved 21 patients who consumed pork from a backyard pig fed on fox carcasses.

Nowadays in France, autochthonous trichinellosis is a well-controlled parasitosis, as only two cases were identified between 2011 and 2014 (Department of Parasitology, Cochin Hospital, in charge of surveillance of human cases in France since 2012). We report an outbreak that occurred in March 2015 in patients living in the South of France (region of Nice) after they consumed raw figatelli, a Corsican sausage bought in Corsica and delivered by post to mainland France.

\section{Case report}

On 5 February 2015, a 59-year-old woman living near Nice (France) received 10 figatelli ordered a few days before from a delicatessen based in Aullène, a village in Southern Corsica. Figatelli sausages are a Corsican specialty prepared from pork products: mainly raw liver, but also raw muscles, heart, and spleen. The woman gave figatelli to 16 friends and ate raw figatelli herself between 13 and 20 February. On 5 March, she went to the hospital due to high fever $\left(40^{\circ} \mathrm{C}\right)$, severe myalgia, facial edema, and conjunctivitis, and was found to have an eosinophil count of $9000 / \mathrm{mm}^{3}$. In the following days, two friends had similar symptoms: a 50-year-old woman who had eaten raw figatelli between 23 and 28 February and who was hospitalized on $12 \mathrm{March}$, and a third person who ate figatelli only once (on 27 February) and who had less severe symptoms. Trichinellosis was not originally diagnosed and it was only at the end of March that Trichinella serology was ordered. On 3 April, three of the patients had specific antiTrichinella antibodies, as detected by ELISA (ImmunoBiological Laboratories, USA) and immunoblotting (LDBio Diagnostics, France). The three patients were treated with albendazole at a dose of $15 \mathrm{mg} / \mathrm{kg}$ for 15 days. One displayed allergic manifestations and required corticosteroids. The outcome was favorable, though visual signs (binocular diplopia, visual discomfort) and residual asthenia lasted for 3 months in two patients. The laboratory signs (abnormal blood eosinophilia and muscle enzymes) rapidly returned to normal after treatment.

Investigation of the outbreak was carried out by the Regional Health Agency (ARS), which was informed of the foodborne outbreak on 4 April 2015. The patient identified as

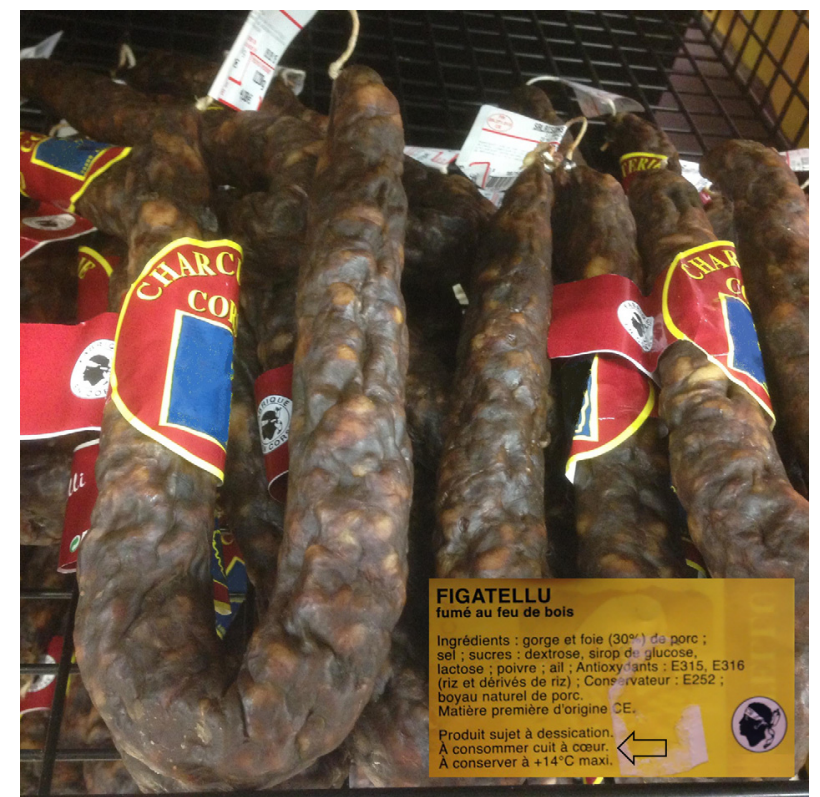

Figure 1. The font size on the figatelli label recommending sufficient cooking of the product ("À consommer cuit à cœur" meaning "cook well before eating") is too small for the warning to be easily read by consumers.

the index case gave figatelli to colleagues, neighbors, and friends without any recommendation on the need for sufficient cooking, though this was written on the label (Fig. 1). In addition to the three affected patients, five different families, comprising 14 people, consumed figatelli from the same batch. All exposed people were asymptomatic at the time of examination, did not mention clinical signs or symptoms suggestive of trichinellosis, and all the laboratory tests performed were normal (blood cell counts, muscle enzymes, Trichinella antibody testing). All figatelli consumed by the 14 exposed people had been well cooked. The Regional Health Agency office in Corsica provided targeted information to consumers and health professionals to raise awareness of the diagnosis of trichinellosis with the suggestive clinical signs and abnormal blood eosinophil counts and emphasized the usual preventive measures.

Veterinary investigation was coordinated by the Laboratory for Animal Health (ANSES) at Maisons-Alfort, France. Three of the ten incriminated figatelli sausages had been kept by the index patient and were analyzed by chlorhydropeptic digestion. A Trichinella burden of 4 larvae per gram was found in the three sausages. The larvae were typed as $T$. britovi by multiplex PCR performed at ANSES. The Official Veterinary Services of Corsica seized all remaining delicatessen products that had been stored and some were found to be parasitized by $T$. britovi larvae. This particular producer breeds his own pigs and usually sends them to a slaughterhouse in Cozzano (a small village of the Taravo valley, $30 \mathrm{~km}$ north of Aullène), where official Trichinella control is performed. In this case, the incriminated products were prepared from pigs that had been illegally slaughtered and not controlled for possible Trichinella infection. 


\section{Discussion}

This small outbreak due to pork consumption is the third reported in France and the first outbreak ever reported after consumption of pork from Corsica. Only two outbreaks related to pork had previously been described in France: the 1878 outbreak in Crépy-en-Valois and the 1983 outbreak in South East France [4, 5]. The emergence of human cases in Corsica was not unexpected, as a focus of swine trichinellosis due to T. britovi had been identified in Cozzano as early as 2004, when ten infected pigs were identified at the local slaughterhouse [11]. Epidemiological studies conducted on foxes from this region enabled detection of one positive animal out of 74. Interestingly, between 2006 and 2008, no wild boar was found to be positive among 1881 animals tested by muscle digestion [11]. Since then, an accredited local routine veterinary laboratory controls all pigs slaughtered locally. This control led to the detection of positive outdoor pigs: three in 2010, four in 2011, six in 2012, and two in 2013 [12]. Similarly, human cases have been reported in the neighboring island of Sardinia, Italy [8]. In April 2005, an outbreak of 11 cases due to the consumption of infected pork was reported to have occurred in the villages of Orgosolo and Lanusei (Nuoro province). Subsequent investigations showed that a second outbreak occurred in December 2005 and artificial digestion of muscle samples from 681 free-range and backyard pigs revealed $T$. britovi larvae in four sows $(0.58 \%)$ [9]. For 60 years, the islands of the Mediterranean Basin were considered to be Trichinella-free, but the emergence of Trichinella infection in Sardinia and Corsica invalidates this concept even though the origin of the infected animals remains to be determined. Recent preliminary results of microsatellite analysis of $T$. britovi isolates from Sardinia, showing genetic differences with both continental and Corsican isolates, suggest different geographic origins and historical introduction of T. britovi to Sardinia. On the contrary, the detection in Corsican isolates of alleles circulating in continental Europe could suggest recent introduction of T. britovi to this island [6]. In France, human trichinellosis is an endemic but rare foodborne parasitosis. Consequently, consumers and the medical community have limited knowledge of the disease, sometimes leading to delayed diagnosis, as described here. Delayed diagnosis of the present outbreak may explain why in two patients visual signs and residual asthenia lasted for 3 months. Consumption of raw figatelli is a cultural tradition in Corsica and the recommendation for sufficient cooking is not always applied. The font size on the figatelli label was too small and inadequate to effectively warn consumers (Fig. 1). The recommendation "to cook well before eating" ( $A$ consommer cuit $\grave{a}$ cœur) should be more visible. Given that there is also a risk of hepatitis E associated with the consumption of raw figatelli [1], we strongly recommend a change to the product labeling to better inform and thus, protect consumers. Finally, as pigs are extensively bred outdoors in Corsica, pork must imperatively be tested at routine accredited veterinary laboratories by specific methods for detection of Trichinella larvae according to EU regulations (Regulation (EC) No. 2075/ 2005 implemented by Regulation (EU) 2015/1375). In the present case, a temporary lack of official control associated with poor information for non-local consumers caused a failure in parasite control, which resulted in trichinellosis in three patients.

\section{Conflict of interest}

The authors have no potential conflicts of interest to disclose.

Acknowledgements. We thank Gordon Langsley for editorial suggestions.

\section{References}

1. Colson P, Borentain P, Queyriaux B, Kaba M, Moal V, Gallian P, Heyries L, Raoult D, Gerolami R. 2010. Pig liver sausage as a source of hepatitis E virus transmission to humans. Journal of Infectious Diseases, 202, 825-834.

2. De Bruyne A, Ancelle T, Vallée I, Boireau P, Dupouy-Camet J. 2006. Human trichinellosis acquired from wild boar meat: a continuing parasitic risk in France. Eurosurveillance, 11, E060914.5.

3. Dupouy-Camet J, Talabani H, Ancelle T. 2010. Trichinellose: une zoonose parasitaire bien contrôlée en France. Revue du Praticien, 60, 159-164.

4. Igual JP, Faugere B, Pene P, Bourgeade A, Quilici M. 1985. Trichinose en Provence : à propos d'une épidémie familiale. Bulletin de la Société de Pathologie Exotique et de ses Filiales, 78, 473-477.

5. Laboulbène JA. 1881. Relation de la première épidémie de trichinose rapportée en France. Bulletin Académie de Médecine 2ème série, 10, 206-228.

6. Marucci G, La Rosa G, Vallée I, Casabianca F, Boireau P, Pozio E. 2015. Microsatellite analysis of Trichinella britovi isolates from the Mediterranean islands of Corsica and Sardinia suggests their different geographical origin. Abstracts of the 14th International Conference on Trichinellosis, Berlin, Germany, 14-18 September 2015, http://www.bfr.bund.de/cm/ 349/ict-14-abstract-book.pdf

7. Murrell KD, Pozio E. 2011. Worldwide occurrence and impact of human trichinellosis, 1986-2009. Emerging Infectious Diseases, 17, 2194-2202.

8. Pozio E, Mesina P, Sechi F, Pira M, Liciardi M, Cossu P, Marucci G, Garippa G, Firinu A. 2006. Human outbreak of trichinellosis in the Mediterranean island of Sardinia, Italy. Veterinary Parasitology, 140, 177-180.

9. Pozio E, Cossu P, Marucci G, Amati M, Ludovisi A, Morales MA, La Rosa G, Firinu T. 2009. The birth of a Trichinella britovi focus on the Mediterranean island of Sardinia (Italy). Veterinary Parasitology, 159, 361-363.

10. Ranque S, Faugère B, Pozio E, La Rosa G, Tamburrini A, Pellissier JF, Brouqui P. 2000. Trichinella pseudospiralis outbreak in France. Emerging Infectious Diseases, 6, 543-547.

11. Richomme C, Lacour SA, Ducrot C, Gilot-Fromont E, Casabianca F, Maestrini O, Vallée I, Grasset A, van der Giessen J, Boireau P. 2010. Epidemiological survey of 
trichinellosis in wild boar (Sus scrofa) and fox (Vulpes vulpes) in a French insular region, Corsica. Veterinary Parasitology, $172,150-154$.

12. Vallée I, Riera M, Richomme C, Lacour S, Zanella G, Casabianca F, Boireau P. 2015. Trichinella in Corsica Island: when the parasite takes advantage of the slightest weak link. Abstracts of the 14th International Conference on Trichinellosis, Berlin, Germany, 14-18 September 2015, http:// www.bfr.bund.de/cm/349/ict-14-abstract-book.pdf

Cite this article as: Ruetsch C, Delaunay P, Armengaud A, Peloux-Petiot F, Dupouy-Camet J, Vallée I, Polack B, Boireau P \& Marty P Inadequate labeling of pork sausages prepared in Corsica causing a trichinellosis outbreak in France. Parasite, 2016, $23,27$.

\section{-0 PARASTE}

An international open-access, peer-reviewed, online journal publishing high quality papers on all aspects of human and animal parasitology

Reviews, articles and short notes may be submitted. Fields include, but are not limited to: general, medical and veterinary parasitology; morphology, including ultrastructure; parasite systematics, including entomology, acarology, helminthology and protistology, and molecular analyses; molecular biology and biochemistry; immunology of parasitic diseases; host-parasite relationships; ecology and life history of parasites; epidemiology; therapeutics; new diagnostic tools.

All papers in Parasite are published in English. Manuscripts should have a broad interest and must not have been published or submitted elsewhere. No limit is imposed on the length of manuscripts.

Parasite (open-access) continues Parasite (print and online editions, 1994-2012) and Annales de Parasitologie Humaine et Comparée (1923-1993) and is the official journal of the Société Française de Parasitologie. 